\title{
Aktivitas Antioksidan Ekstrak Daun Mangrove Rhizopora mucronata
}

\author{
Ali Ridlo*, Rini Pramesti, Koesoemadji, Endang Supriyantini, Nirwani Soenardjo \\ Departemen Ilmu Kelautan, Fakultas Perikanan dan Ilmu Kelautan, Universitas Diponegoro \\ Kampus Tembalang, Semarang 50275 Telp/Fax. 024-7474698 \\ Email: aliridlo26@gmail.com
}

\begin{abstract}
Abstrak
Rhizopora mucronata merupakan salah satu jenis mangrove yang berpotensi sebagai sumber antioksidan alami. Daun tanaman ini mengandung senyawa metabolit sekunder seperti tanin, fenolat, klorofil, karotenoid dan alkaloid. Penelitian ini bertujuan menentukan aktivitas antioksidan ekstrak daun $R$. mucronata. Sampel diambil dari kawasan mangrove Tugurejo, Semarang dan diekstraksi secara bertingkat berturut-turut dengan pelarut n-heksana, etil asetat dan metanol. Aktivitas antioksidan diukur dengan metode DPPH (1,1-diphenyl-2-picrylhidrazyl) dan nilainya ditentukan berdasarkan nilai Inhibitory Concentration $\left(\mathrm{IC}_{50}\right)$ pada panjang gelombang $516,5 \mathrm{~nm}$. Kadar senyawa fenolat total ditentukan secara spektrofotometri pada panjang gelombang $725 \mathrm{~nm}$ dengan metode Folin-Ciocalteu, kadar klorofil a dan b ditentukan dengan metode spektrofotometri pada panjang gelombang $663 \mathrm{~nm}$ dan $645 \mathrm{~nm}$ dan kadar karotenoid diukur pada 480 nm. Hasil penelitian menunjukkan ekstrak metanol memiliki nilai IC 50 terkecil (113,41 ppm), diikuti ekstrak n-heksana 151,13 ppm dan ekstrak etil asetat 184,78 ppm. Kandungan total fenolat tertinggi terdapat pada ekstrak metanol yaitu 21,06 mg GAE/g sampel, ekstrak n-heksana 13,27 mg GAE/g sampel dan ekstrak etil asetat 2,08 mg GAE/g sampel. Kandungan klorofil a tertinggi terdapat pada ekstrak metanol yaitu 2,304 $\mathrm{mg} / \mathrm{g}$, diikuti ekstrak n-heksana $0,705 \mathrm{mg} / \mathrm{g}$ dan ekstrak etil asetat $0,64 \mathrm{mg} / \mathrm{g}$. Kandungan klorofil b tertinggi dicapai ekstrak metanol yaitu $0,97 \mathrm{mg} / \mathrm{g}$, ekstrak n-heksana 0,50 mgg dan ekstrak etil asetat $0,13 \mathrm{mg} / \mathrm{g}$. Kandungan karotenoid tertinggi dicapai pada ekstrak metanol yaitu 6,49 mg GAE/g, diikuti ekstrak etil asetat (0.54 mg GAE/g) dan ekstrak n-heksana (1,37 mg GAE/g). Ekstrak metanol memiliki aktivitas antioksidan tertinggi dan termasuk dalam antioksidan kategori sedang, sedangkan ekstrak etil asetat dan nheksana termasuk dalam antioksidan kategori lemah.
\end{abstract}

Kata kunci: Rhizopora mucronata, Antioksidan, DPPH

\section{Abstract}

Rhizopora mucronata is one type of mangrove that has the potential as a source of natural antioxidants. The leaves of this plant contain secondary metabolite compounds such as tannins, phenolics, chlorophyll, carotenoids and alkaloids. This study aims to determine the antioxidant activity of R. mucronata leaf extract. Samples were taken from Tugurejo mangrove area, Semarang and extracted successively with n-hexane, ethyl acetate and methanol solvent. Antioxidant activity was measured by DPPH (1,1-diphenyl-2picrylhidrazyl) method and its value was determined based on Inhibitory Concentration (IC 50$)$ value at 516,5 $\mathrm{nm}$ wavelength. Total phenolic compound concentration was determined spectrophotometrically at $725 \mathrm{~nm}$ wavelength with Folin-Ciocalteu method. The levels of chlorophyll $a$ and $b$ was determined by spectrofotometry method at $663 \mathrm{~nm}$ and $645 \mathrm{~nm}$ wavelength and carotenoid levels were measured at $480 \mathrm{~nm}$. The results showed that methanol extract had the smallest IC50 value (113,41 ppm), followed by $n$-hexane extract 151,13 ppm and ethyl acetate extract 184,78 ppm. The highest total phenolic content was found in methanol extract, $21.06 \mathrm{mg}$ GAE / g sample, $n$-hexane extract 13,27 mg GAE / g sample and ethyl acetate extract $2.08 \mathrm{mg}$ GAE / g sample. The highest content of chlorophyll a contained in methanol extract is 2,304 $\mathrm{mg} / \mathrm{g}$, followed by $\mathrm{n}$-hexane extract $0,705 \mathrm{mg} / \mathrm{g}$ and ethyl acetate extract $0,64 \mathrm{mg} / \mathrm{g}$. The highest content of chlorophyll $b$ was methanol extract of $0.97 \mathrm{mg} / \mathrm{g}, \mathrm{n}$-hexane extract $0,50 \mathrm{mgg}$ and ethyl acetate extract $0,13 \mathrm{mg} / \mathrm{g}$. The highest carotenoid content was achieved in the methanol extract of $6.49 \mathrm{mg} G A E / \mathrm{g}$, followed by ethyl acetate extract $(0.54 \mathrm{mg}$ GAE / g) and n-hexane extract (1.37 mg GAE / g). Methanol extract has the highest antioxidant activity and is included in medium category antioxidants, while ethyl acetate and n-hexane extracts are included in weak category antioxidants.

Keyword: Rhizopora mucronata, Antioxidant, DPPH

\begin{tabular}{llll}
\hline *Corresponding author & http://ejournal.undip.ac.id/index.php/buloma & Diterima/Received & $: 17-05-2017$ \\
buloma.undip@gmail.com & & Disetujui/Accepted & $: 01-08-2017$
\end{tabular}





\section{PENDAHULUAN}

Antioksidan adalah senyawa atau zat yang dapat menghambat, menunda, mencegah atau memperlambat reaksi oksidasi meskipun dalam kosentrasi yang kecil. Oksidasi adalah reaksi kimia yang dapat menghasilkan radikal bebas sehingga memicu reaksi berantai (chain reaction). (Ghosal et al., 1996). Radikal bebas merupakan salah satu penyebab timbulnya berbagai penyakit degeneratif seperti kanker, aterosklerosis, stroke, gagal ginjal, hipertensi, katarak, penuaan dini dan penyakit kronik lainnya (Saha et al., 2008; Prasad et al., 2009).

Aktivitas radikal bebas dapat diredam dengan pemberian antioksidan (Kubola \& Siriamornpun, 2008; Mohsen \& Ammar 2009). Antioksidan juga penting dalam mempertahankan mutu bahan dan produk pangan, serta mampu menghambat kerusakan pangan seperti ketengikan (rancidity), perubahan warna dan aroma, perubahan tekstur, perubahan nilai gizi, mencegah kerusakan oksidatif minyak dan dapat mempertahankan nilai gizi serta meningkatkan umur simpan bahan pangan (Winarno, 1984)

Antioksidan alami relatif aman dan dapat menambah kandungan nutrisi pada bahan pangan, sehingga penggunaannya semakin diminati sehingga perlu dilakukan usaha dan kajian guna mengeksplorasi sumber-sumber baru antioksidan alami untuk menggantikan ataupun mengurangi penggunaan antioksidan sintetik. Keuntungan antioksidan sintetik adalah aktivitas antiradikalnya sangat kuat, namun antioksidan sintetik BHA dan BHT berpotensi karsinogenik (Wichi,1988; Thompson \& Moldeus, 1988).

Indonesia kaya akan sumber daya alam yang dapat dimanfaatkan sebagai sumber antioksidan alami, salah satunya adalah mangrove Rizophora mucronat. Tanaman ini mengandung senyawa metabolit skunder seperti tanin, senyawa fenolat, klorofil, karotenoid dan alkaloid. Buahnya dijadikan bahan makanan dan minuman, daun yang masih muda digunakan sebagai sayuran, kayu dan kulit kayu digunakan sebagai bahan penyamak (tanning) dan zat warna, air rebusan kayu (ekstrak) dapat digunakan sebagai obat pelangsing, antidiare dan antimuntah (Abidin et al., 2013)

Daun $R$. mucronata mengandung 2-(2etoksi etanol, kau-16-ena dan benzophenon, senyawa fenolik golongan flavonoid, asam fenolat, dan tannin dihidroflavonol, asam kafeat, asam vanilat, asam $\mathrm{p}$-hidroksi benzoate, dan tanin. alkaloid, kumarin, flavonoid, fenol dan polifenol, quinon, resin, saponin, fitosterol, tanin, xanthoprotin, pigmen (klorofil, karotenoid) dan gula (Babuselvam et al., 2012; Abidin et al., 2013). Tanaman ini berpotensi sebagai antibakteri, antimalaria, antiviral dan antioksidan (Abidin et al., 2013; Purwaningsih et al., 2013; Yogananth, et al., 2015).

Penelitian ini bertujuan menentukan aktivitas antioksidan ekstrak daun mangrove $R$. mucronata dengan metoda transfer elektron radikal bebas DPPH (1,1-difenil-2-pikrilhidrazil). Pengukuran aktivitas antioksidan dilakukan pada panjang gelombang 516,5 nm. Aktivitas antioksidan ditunjukkan dengan terjadinya perubahan warna larutan DPPH dari ungu tua menjadi kuning pucat (Permana et al., 2003). Aktivitas antioksidan dinyatakan dalam Inhibitory Concentration $50\left(\mathrm{IC}_{50}\right)$

\section{MATERI DAN METODE}

Materi yang digunakan dalam penelitian adalah daun mangrove $R$. mucronata yang diambil secara purposive pada bagian tengah ranting pohon, umurnya tidak terlalu tua (pangkal) atau terlalu muda (pucuk) dari kawasan mangrove Tugurejo, Semarang.

\section{Analisis Kadar Air Daun R. mucronata}

Cawan kosong dipanaskan dalam oven pada suhu $100 \quad{ }^{\circ} \mathrm{C}$ selama 15 menit kemudian didinginkan dalam desikator selama 20 menit. Sampel sebanyak $15 \mathrm{~g}$ disimpan dalam cawan yang telah didinginkan dalam desikator, kemudian dikeringkan dengan oven pada suhu $100{ }^{\circ} \mathrm{C}$ selama 30 menit atau sampai beratnya konstan kemudian didinginkan dalam desikator dan ditimbang. Kadar air dihitung menggunakan rumus: (AOAC, 1984) :

$$
\text { Kadar air }(\%)=\frac{(b-c)}{(b-a)} \times 100 \%
$$

$$
\begin{aligned}
& \text { Keterangan } \\
& \mathrm{a}=\text { berat cawan kosong } \\
& \mathrm{b}=\text { berat cawan }+ \text { sampel sebelum dikeringkan } \\
& \mathrm{c}=\text { berat cawan }+ \text { sampel setelah dikeringkan }
\end{aligned}
$$

\section{Ekstraksi Sampel}

Ekstraksi dilakukan dengan cara maserasi bertingkat berturut-turut menggunakan n-heksana, etil asetat, dan metanol (Setha et al., 2013). Sampel sebanyak $150 \mathrm{~g}$ dipotong $\pm 5 \mathrm{~mm}$, dimaserasi dalam n-heksana sebanyak $400 \mathrm{~mL}$ selama 24 jam pada suhu ruang $\pm 27^{\circ} \mathrm{C}$, lalu disaring. Residu dimaserasi kembali selama 24 jam dan disaring, lalu filtrat diuapkan 
menggunakan rotary evaporator pada suhu 37 ${ }^{\circ} \mathrm{C}$. Residu dimaserasi kembali berturut-turut dalam etil asetat dan metanol dengan cara yang sama seperti di atas, kemudian dievaporasi sampai diperoleh ekstrak.

\section{Uji Kualitatif Antioksidan}

Lima mg ekstrak dilarutkan dalam $5 \mathrm{~mL}$ methanol, lalu diukur absorbansinya pada panjang gelombang 400 sampai dengan $800 \mathrm{~nm}$. Langkah yang sama dilakukan pada ekstrak yang ditambahkan DPPH dan telah diinkubasi selama 30 menit. Hilangnya puncak absorbansi pada panjang gelombang 516,5 $\mathrm{nm}$ menunjukkan DPPH telah bereaksi sempurna dengan ekstrak. Secara visual, uji positif ditandai dengan terjadinya perubahan warna larutan dari ungu tua menjadi kuning pucat (Permana et al, 2003).

\section{Uji Aktivitas Antioksidan}

Tiga $\mathrm{mL}$ larutan ekstrak dengan konsentrasi 50, 100, 150, 200, 250, 300, 350, 400 ppm ditambahkan $1 \mathrm{~mL}$ DPPH $0,1 \mathrm{mM}$, kemudian diinkubasi selama 30 menit pada suhu ruang (27 $\left.{ }^{\circ} \mathrm{C}\right)$. Setelah itu diukur absorbansinya pada panjang gelombang $516,5 \mathrm{~nm}$. Aktivitas inhibisi dihitung menggunakan rumus (Setha et al., 2013):

Persentase Inhibisi $=\frac{(\mathrm{A}-\mathrm{B})}{\mathrm{A}} \times 100 \%$

Keterangan :

$\mathrm{A}=$ absorbansi larutan DPPH

$\mathrm{B}=$ absorbansi DPPH + Ekstrak

\section{Pengukuran Kandungan Total Fenolat}

Uji kandungan total fenolat ekstrak dilakukan dengan metode Folin-Ciocalteu dengan asam galat sebagai standard (Mohsen dan Ammar, 2009). Disiapkan sebanyak $2 \mathrm{~mL}$ Asam galat dengan konsentrasi 5, 10,15, 20 dan $25 \mathrm{ppm}$, kemudian ditambahkan $5 \mathrm{~mL}$ akuades dan 0,5 $\mathrm{mL}$ reagen Folin-Ciocalteu. Larutan didiamkan selama 3 menit kemudian ditambahkan $1 \mathrm{~mL}$ larutan $\mathrm{Na}_{2} \mathrm{CO}_{3} 5 \%$ dan diinkubasi pada suhu ruang selama 1 jam dalam kondisi gelap. Absorbansi diukur pada panjang gelombang 725 nm (Ghafar, 2010), selanjutnya dibuat kurva standar antara konsentrasi asam galat versus nilai absorbansinya sehingga diperoleh grafik garis lurus. Langkah yang sama dilakukan pada masing-masing ekstrak. Kandungan total fenolat dihitung menggunakan rumus (Ghafar, 2010):

$$
\mathrm{TF}=\frac{(\mathrm{a} \times \mathrm{V}) / 1000}{\mathrm{G}}
$$

Keterangan

$\mathrm{TF}=$ Kandungan total fenolat (mg Galic Acid Equivalent (GAE)/1000 g

$\mathrm{a}=$ Konsentrasi asam galat dalam ekstrak $(\mathrm{mg} / \mathrm{L})$

$\mathrm{V}=$ Volume total larutan uji $(\mathrm{mL})$

$\mathrm{G}=$ Berat ekstrak yang digunakan $(\mathrm{g})$

\section{Pengukuran Kandungan Klorofil a, klorofil n dan Karotenoid}

Penentuan kandungan klorofil a, b dan karotenoid dilakukan dengan metode spektrofotometri. Ekstrak dilarutkan dalam aseton p.a dengan konsentrasi 100 ppm dan diukur absorbansinya pada panjang gelombang $645 \mathrm{~nm}, 663 \mathrm{~nm}$ dan $480 \mathrm{~nm}$. Kandungan klorofil dan karotenoid dihitung (Gross, 1991) :

$$
\begin{aligned}
& \text { Klorofil a } \quad=12,7 \times \mathrm{A}_{663}-2,69 \times \mathrm{A}_{645} \\
& \text { Klorofil b } \quad=22,9 \times \mathrm{A}_{645}-4,68 \times \mathrm{A}_{663} \\
& \text { Karotenoid = } \\
& \underline{(\mathrm{A} 480+(0,114 \times \mathrm{A} 663)-(0,638 \times \mathrm{A} 645) \times \mathrm{V} \times 1000} \\
& 112,5 \times 0,1 \times 10
\end{aligned}
$$

\section{HASIL DAN PEMBAHASAN}

Daun mangrove $R$. mucronata segar yang digunakan sebagai sampel penelitian diambil dari daerah Tugurejo Kodya Semarang. Hasil penelitian menunjukkan kadar air sampel adalah $16,6 \%$. Secara umum kadar air pada daun mangrove relatif rendah. Hal ini diduga habitat mangrove yang bersalinitas dan suhu tinggi karena pengaruh transfer panas dari laut. Kadar air yang diperoleh pada penelitian ini lebih rendah daripada daun mangrove Bruguiera gymnorrhiza yaitu 74,72 \% (Dia et al., 2015). Ditambahkan oleh Krzynowek dan Murphy (1987) adanya perbedaan kadar air untuk beberapa spesies tergantung pada musim dan lokasi pengambilan sampel.

Sampel diekstraksi secara bertingkat dengan pelarut $n$-heksana, etil asetat dan metanol agar senyawa yang terkandung dapat terekstraksi semua, karena ke tiga pelarut tersebut akan melarutkan senyawa sesuai dengan tingkat kepolarannya (Sarastani et al., 2002). Senyawa non polar seperti lipida dan lilin akan terlarut dalam n-heksana, senyawa semi polar seperti klorofil akan terlarut dalam etil asetat sedangkan senyawa polar seperti senyawa fenolat, alkaloid, dan asam-asam organik akan terlarut dalam metanol (Kuppusamy et al., 2015).

Rendemen tertinggi dicapai pada ekstraksi dengan metanol yaitu $4,9 \mathrm{~g}(3,27 \%)$ diikuti ekstrak etil asetat dan n-heksana. Hal ini 
menunjukkan daun mangrove $R$. mucronata banyak mengandung senyawa yang besifat polar. Secara visual ekstrak metanol berwarna hijau kecoklatan, ekstrak etil asetat berwarna hijau kecoklatan dan ekstrak n-heksana berwarna coklat kekuningan. Warna hijau diduga adalah warna klorofil, sedangkan warna coklat diduga berasal dari karotenoid dan pigmen lain. Hasil ekstraksi ditampilkan pada Tabel 1 .

Tabel 1. Hasil ekstraksi daun mangrove $R$. Mucronata

\begin{tabular}{ccc}
\hline Pelarut & Rendemen (\%) & Warna \\
\hline Metanol & 3,27 & Hijau Kecoklatan \\
Etil Asetat & 2,32 & Hijau Kecoklatan \\
n-Heksana & 0,18 & Coklat Kekuningan \\
\hline
\end{tabular}

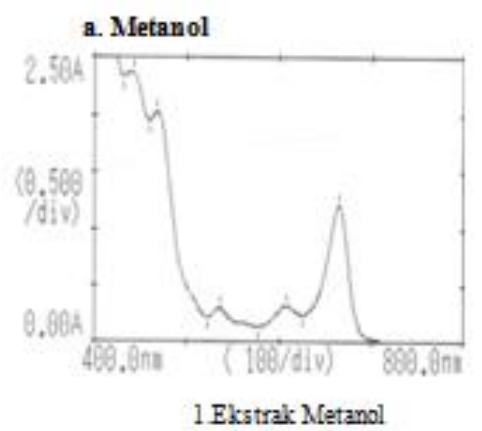

b. Etil Asetat
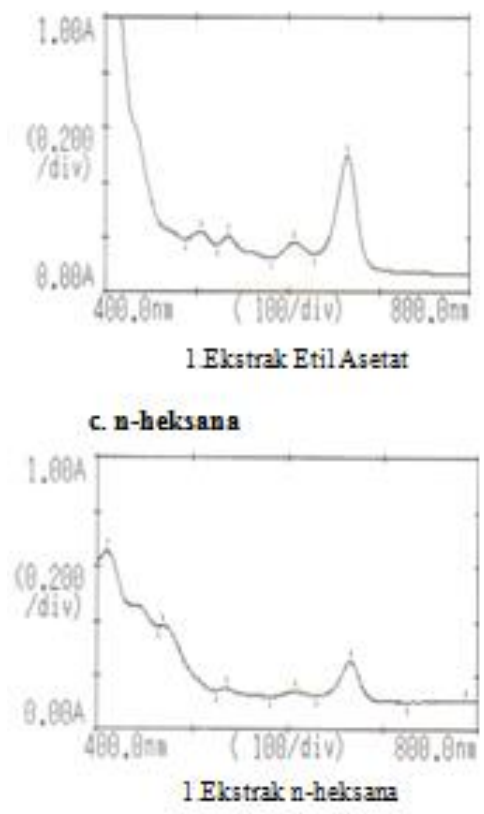

Ketiga ekstrak mengandung klorofil dan karotenoid, yang ditunjukkan dengan adanya puncak pada panjang gelombang klorofil 400 $450 \mathrm{~nm}$ dan 650 - $700 \mathrm{~nm}$ dan panjang gelombang karotenoid pada $400-500 \mathrm{~nm}$ (Limantara et al., 2008) (Gambar 3). Aktivitas antioksidan secara kualitatif dapat diketahui dengan cara membandingkan antara spektra ekstrak dengan spektra ekstrak yang ditambah DPPH. Panjang gelombang absorbansi maksimum $\left(\lambda_{\max }\right) \mathrm{DPPH}$ yang semula muncul pada 516,5 nm (Gambar 1), ketika di tambah ekstrak daun mangrove $R$. mucronata menjadi hilang (Gambar 3). Hal ini menunjukkan bahwa DPPH telah bereaksi sempurna dengan ekstrak daun mangrove $R$. mucronata dan membentuk DPPH-H. Hal ini secara visual dapat diamati dari perubahan warna DPPH dari ungu tua menjadi kuning pucat.
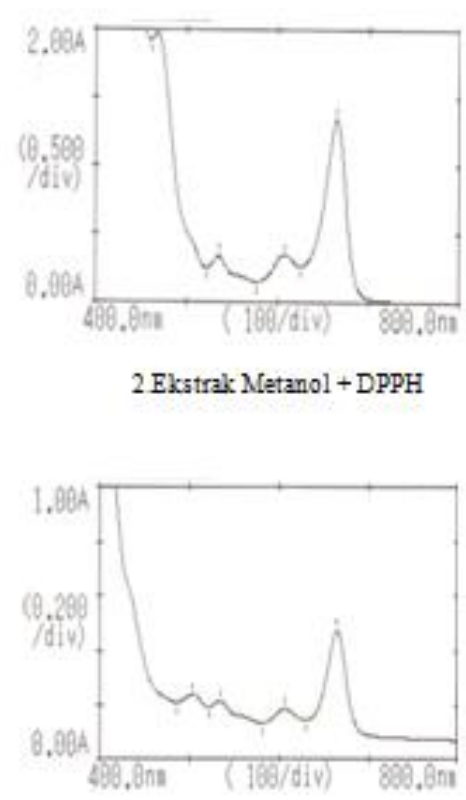

2 Ekstrak: Etil Asetat+DPPH

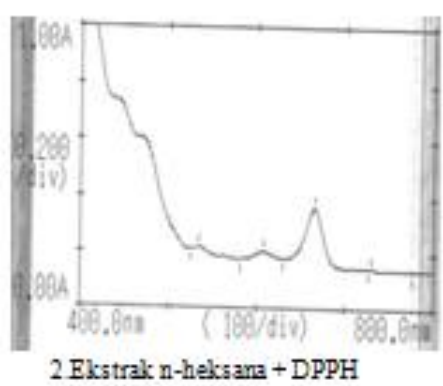

Gambar 1. Spektra $\left(a_{1}\right)$ ekstrak metanol, $\left(b_{1}\right)$ ekstrak etil asetat, $\left(c_{1}\right)$ ekstrak n-heksana, $\left(a_{2}\right)$ ekstrak metanol + DPPH, $\left(b_{2}\right)$ ekstrak etil asetat + DPPH, $\left(c_{2}\right)$ ekstrak n-heksana + DPPH 


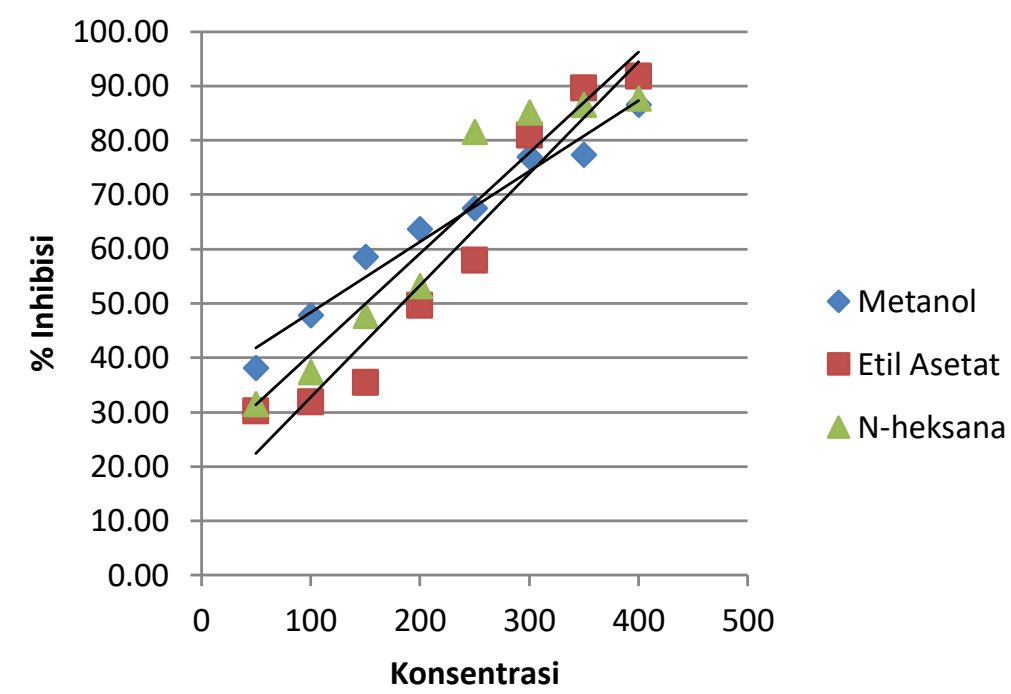

Gambar 2. Aktivitas antioksidan $R$. mucronata

Tabel 2. Kandungan total fenolat dan pigmen dalam Ekstrak daun R. Mucronata

\begin{tabular}{|c|c|c|c|}
\hline \multirow[t]{2}{*}{ Parameter yang Diukur } & \multicolumn{3}{|c|}{ Pelarut } \\
\hline & Metanol & Etil Asetat & n-heksana \\
\hline Total Fenolat (mg GAE/g) & 21,06 & 2,08 & 13,27 \\
\hline Klorofil a (mg/g) & 2,304 & 0,640 & 0,705 \\
\hline Klorofil b (mg/g) & 0,97 & 0,13 & 0,50 \\
\hline Karotenoid $(\mu \mathrm{mol} / \mathrm{g})$ & 6,49 & 0,54 & 1,37 \\
\hline
\end{tabular}

Nilai antioksidan ekstrak ditentukan berdasarkan nilai $\mathrm{IC}_{50}$ yaitu konsentrasi larutan ekstrak yang menyebabkan reduksi aktivitas DPPH sebesar 50\%. Persentase inhibisi ditentukan dengan membandingkan absorbansi DPPH murni terhadap absorbansi DPPH yang ditambah ekstrak pada panjang gelombang 516,5 nm. Hasil penelitian menunjukkan inhibisi DPPH oleh ekstrak berbanding lurus dengan konsentrasi ekstrak, yang berarti semakin besar konsentrasi ekstrak, persentase inhibisinya juga semakin tinggi.

Ekstrak n-heksana memiliki nilai $\mathrm{IC}_{50}$ $151,13 \mathrm{ppm}$, ekstrak etil asetat 184,78 ppm, dan ekstrak metanol 113,41 ppm. Ekstrak metanol mempunyai nilai $\mathrm{IC}_{50}$ terkecil, yang berarti ekstrak metanol memiliki aktivitas yang paling baik dalam meredam radikal bebas DPPH dibandingkan ekstrak etil asetat dan n-heksana. Hal ini menunjukkan ekstrak metanol memiliki aktivitas antioksidan paling kuat dibanding ekstrak etil asetat dan n-heksana. Hal ini diduga kandungan total fenolat, klorofil a, klorofil b dan karotenoidnya lebih tinggi dibandingkan ekstrak n-heksana dan ekstrak metanol (Tabel 2) (Kuppusamy et al., 2015). Senyawa tersebut mampu meredam aktivitas radikal bebas, dapat langsung bereaksi dengan radikal bebas dan mengubahnya menjadi radikal bebas baru yang kurang reaktif dan kurang berbahaya (Amic et al., 2003).

Senyawa fenolat bekerja sebagai antioksidan melalui pemutusan reaksi berantai (chain reaction) radikal dan mendonorkan atom hidrogennya sehingga dihasilkan radikal bebas yang lebih stabil (Nimse \& Pal, 2015). Klorofil bekerja dengan menangkap radikal bebas (Sayuti \& Yenrina, 2015), sedangkan karotenoid bekerja dengan meredam singlet oksigen (Nimse \& Pal, 2015). Bioaktivitas karotenoid dipengaruhi oleh jumlah ikatan rangkap, rantai terbuka serta jumlah substituen oksigennya (Sayuti \& Yenrina, 2015).

Senyawa fenolat berfungsi sebagai senyawa pelindung tumbuhan dari kerusakan akibat cahaya yang berlebihan dengan bertindak sebagai antioksidan, dan kekuatannya bervariasi 
tergantung pada kondisi lingkungannya (Close \& McArthur, 2002). Senyawa fenolat dapat melindungi daun mangrove dari kerusakan akibat radiasi ultraviolet (Agati et al., 2007) dan peningkatan produksi senyawa fenolat pada mangrove terjadi saat pertumbuhan dan beradaptasi dalam kondisi tertekan (Banerjee et al., 2008).

Kemampuan antioksidan ekstrak yang diamati lebih tinggi dibandingkan aktivitas antioksidan Avicennia marina yang memiliki nilai $\mathrm{IC}_{50} 182,33 \mathrm{ppm}$ dan tergolong antioksidan lemah (Jacoeb et al., 2011). Hal ini diduga $R$. mucronata mampu beradaptasi yang lebih baik dibandingkan A. marina sehingga dapat mempengaruhi senyawa aktif di dalamnya. Aktivitas antioksidan ekstrak tumbuhan tergantung pada jenis spesies, metode ekstraksi, musim dan lokasi pengambilan sampel (Budhiyanti et al., 2012).

\section{KESIMPULAN}

Aktivitas antioksidan ekstrak daun mangrove $R$. mucronata terbaik terdapat pada ekstrak metanol dengan nilai $\mathrm{IC}_{50} 113,41 \mathrm{ppm}$ dan termasuk antioksidan kategori sedang/menengah.

\section{DAFTARPUSTAKA}

Abidin, N. A. Z. Halim N. A. H. and Ropisah. 2013. Basic Study of Chemical Constituents in $R$. mucronata Species. The Open Conference Proceedings Journal, 4(Suppl-2, M7) 27-28. Faculty of Applied Science, Universiti Teknologi MARA Negeri Sembilan, Ka. Malaysia

Agati, G, Matteini, P, Goti, A, dan Tattini, M. 2007. Chloroplast Located Flavonoids can Scavenge Singlet Oxygen. New Phytologist.,174: 77-82.

Amic A., D.Davidovic-amic, D. Beslo dan N. Trinajstic. 2003. Structure-Radical Scavenging Activity Relationships of Flavonoids. Journal of Croatica Chemica Acta., 76(1): 55-61.

AOAC. 1984. Official Methods of Analysis of the Association of Official Analitycal Chemist. Inc. Washington DC. P. 185 - 189

Babuselvam, M., K. Kathiresan, S. Ravikumar, M. Uthiraselvam, dan E. Rajabudeen. 2012. Scientific Evaluation of Aqueous Extracts of Lresh and Dried Leaves from Rhizophora mucronata lamk (Rhizophoracea) in Rats. African Journal of Pharmacy and Pharmacology, 6 (11): 814-817.

Banerjee, D., Chakrabarti. S., Hazra.A.K., Banerjee.S., Ray.J., dan Mukherjee, B. 2008.
Antioxidant Activity and Total Phenolics of some Mangroves in Sundarbans. African Journal of Biotechnology., 7: 805-810.

Budhiyanti, S.A., S. Raharjo, D.W. Marseno dan I.Y.B. lelana. 2012. Antioxidant Activity of Brown Algae Sargassum Species Extract from the Coastline of Java Island. American Journal of Agricultural and Biological Sciences., 7(3): 337-346.

Close, D.C. dan McArthur,C. 2002. Rethinking the Role of many Plant Phenolics Protection from Photodamage not Herbivores. 99: 166-172.

Dia, S.P.S., Nurjanah dan A.M. Jacoeb. 2015. Komposisi Kimia dan Aktivitas Antioksidan Akar, Kulit Batang dan Daun Lindur. JPHPI., 18(2): 206-219.

Ghafar, M.F.A., K.N. Prasad., K.K. Weng dan A. Ismail. 2010. Flavonoid, Hesperidine, Total Phenolic Contents and Antioxidant Activities from Citrus $s p$. African Journal of Biotechnology., 9(3): 326-330

Gross, J. 1991. Pigments In Vegetables. Chlorophylls and Carotenoids. An Avi Book. Van Nostrand Reinhold, New York.

Jacoeb, A. M. , S. Purwaningsih, Rinto. 2011. Anatomi, Komponen Bioaktif dan Aktivitas Antioksidan Daun Mangrove Api-api (Avicennia marina). Jurnal Pengolahan Hasil Perikanan Indonesia., 14(2) : 143-152.

Krzynowek J, Murphy J. 1987. Proximate Composition, energy, fatty acid, sodium and Cholesterol content of Finfish, Shellfish, and Their Products. Technical Report NMFS 55. United States, NOOA.

Kubola J., S. Siriamornpun. 2008. Phenolic Contents and Antioxidant Activities of Bitter Gourd (Momordica carantia L.) Leaf, Stem and Fruit Fraction Extracts in vitro. Food Chemistry $110: 881-890$.

Kuppusamy P., M.M. Yusoff, N.R. Parine dan N. Govindan. 2015. Evaluation of In-vitro Antioxidant and Antibacterial Properties of Commelina nudiflora L. Extracts Prepared by Different Polar Solvents. Saudi Journal of Biological Sciences., 22: 293-301.

Limantara, L., R. Christiana dan H. Kristopo. 2008. Fotodegradasi dan Aktivitas Antioksidan Klorofil a dari Serbuk Spirulina (Spirulina sp.). Jurnal Chemistry., 8(2): 236241.

Nimse, S.B. dan D. Pal. 2015. Free Radicals, Natural antioxidants, and Their Reaction Mechanisms. Journal of Royal Society of Chemistry., 5: 27986-28006. 
Patria, W.D. dan C.J. Soegihardjo. 2013. UJI Aktivitas Antioksidan menggunakan Radikal 1,1-Difenil-2-Pikrilhidrazil (DPPH) dan Penetapan Kandungan Fenolik Total Fraksi Etil Asetat Ekstrak Etanolik Daun Benalu (Dendrophthoe Pentandral.Miq.) yang Tumbuh di Pohon Kepel (S. burahol (Bl.) Hook. F.). Jurnal Farmasi Sains., 10(1):5160.

Permana, D., Lajis, N. Abas, F., Othman, A. G. Ahmad, R. Kitajama,M. Takayama, H. Aimi, N. 2003. Antioxidative Constituents of Hedotis Diffusa Wild. Vol. 9, No. 1, Hlm. 79

Prasad N. P. Yang, B. Dong, X. Jiang G. Zhang, H. Xie H. Jiang Y. 2009. Flavonoid Contents and Antioxidant Activities from Cinnamomum sp. Journal Innovative Food Science and Emerging Technologies 10: 627632.

Purwaningsih, S., E. Salamah, Y.P. Sukarno dan E. Deskawati. 2013. Aktivitas Antioksidan Dari Buah Mangrove (Rhizophora mucronata Lamk.) pada Suhu Yang Berbeda. JPHPI., 16(3): 199-206.

Saha M. R, Hasan S. M. R, Akter R, Hossain M. M, Alam M. S, Alam M. A, Mazumder M. E. H. 2008. In Vitro free Radical Scavenging Activity of Methanol Extract of the Leaves of Mimusops lengi linn. Bangladesh Journal of Veteriner Medicine 6(2):197-200
Sarastani, D., S.T. Soekarto, T.R. Muchtadi, D. Fardiaz dan A. Apriyantono. 2002. Aktivitas Antioksidan Ekstrak dan Fraksi Ekstrak Biji Antung (Parinarium glaberrimum). Jurnal Teknologi dan Industri Pangan., 13(2): 149156.

Sayuti, K. dan R. Yenrina. 2015. Antioksidan Alami dan Sintetik. Andalas University Press, Padang.

Setha, B., F.F. Gasperzs, A.P.S. Idris, S. Rahman dan M.N. Mailoa. 2013. Potential of Seaweed Padina Sp. as a Source of Antioxidant. International Journal of Scientific and Technology Research., 3(6): 221-224.

Wichi H. P. 1988. Enhanced Tumour Development by Butylated Hydroxytoluene (BHT) from the Properties of Effect on Fure Stomach and Esophageal Aquamoua Epithelium. Food Chemical toxicology 26:727-723.

Winarno F.G. 1984. Kimia Pangan dan Gizi. Gramedia, Jakarta.

Yogananth, N., V. Anuradha, M. Y. S. Ali., R. Muthezhilan., A. Chanthuru. 2015. Chemical Properties of Essential Oil From $R$. mucronata mangrove Leaf Against Malarial Mosquito Anopheles stephensi and Filarial Mosquito Culex quinquefasciatus. Asian Pacific Journal of Tropical Disease., 5(1): 67-79. 